\title{
Does Low-Dose Heparin Have a Significant Role in Free Flap Surgery?
}

\author{
Mun-Young $\mathrm{An}^{1}$, \\ Jin Yong Shin ${ }^{1}$, \\ Young-Keun Lee', \\ M. Diya Sabbagh ${ }^{3}$, \\ Si-Gyun Roh ${ }^{1,3}$, \\ Nae-Ho Lee ${ }^{1}$ \\ ${ }^{1}$ Department of Plastic and Reconstructive \\ Surgery, Chonbuk National University \\ Hospital, Jeonju; \\ ${ }^{2}$ Department of Orthopedic Surgery, Chonbuk \\ National University Medical School, Jeonju, Korea; \\ ${ }^{3}$ Division of Plastic Surgery, Department of \\ Surgery, Mayo Clinic, Rochester, MN, USA
}

No potential conflict of interest relevant to this article was reported.

\begin{abstract}
Background: It is controversial issue that heparin decreases thrombosis for microsurgical anastomosis, and its effective role is under discussion. This study is for proving whether low-dose heparin is preventing thrombosis in free flap reconstruction.

Methods: Through chart reviews of 134 patients, using low-dose heparin for free tissue transfer from 2011 to 2016, retrospective analysis was performed. 33 patients received lowdose heparin therapy after surgery. And 101 patients received no-heparin therapy. Complications included flap necrosis, hematoma formation, dehiscence and infection.

Results: In no-heparin therapy group, comparing the flap necrosis revealed 16 cases $(15.84 \%)$. And, flap necrosis was 6 cases $(18.18 \%)$ in low-dose heparin therapy group. The statistical analysis of flap necrosis rate showed no significant difference $(p=0.75)$. The results showed that there was no significant difference of flap necrosis rate between two groups.

Conclusion: In this study, patients in the low-dose heparin group had no significantly lower rates of flap failure compared with no-heparin group. This suggests that low-dose heparin may not prevent thrombosis and subsequent flap failure to a significant extent.
\end{abstract}

Keywords: Heparin / Free tissue flaps / Necrosis / Hematoma

\section{INTRODUCTION}

Currently, free flap is considered to be a common and reliable surgical technique for covering large defects [1,2]. However, about $1 \%-4 \%$ of patients who underwent free tissue transfer had suffered flap failure due to microvascular thrombosis, anastomotic failure, mechanical obstruction, tension and compression [3-5]; therefore, improvement is still necessary. Especially, in flap failure with thrombosis, arterial thrombus generally develops during the first 24 hours and venous thrombus forms in the second postoperative day $[6,7]$.

It is common for prophylactic antithrombotic agents to be used to prevent microvascular thrombosis in the free flap [8,9]. Many

\section{Correspondence: Jin Yong Shin}

Department of Plastic and Reconstructive Surgery, Chonbuk National University Hospital, 20 Geonji-ro, Deokjin-gu, Jeonju 54907, Korea

E-mail: psjyshin@gmail.com

Received May 30, 2017 / Revised September 4, 2017 / Accepted September 4, 2017 surgeons considered several methods of antithrombotic pathways clinically: Antiplatelet method, anticoagulant method, and blood viscosity reduction method and so on [10-14]. However, according to the recent study, they suggested that these antithrombotics could not reduce the risk of total flap loss or thrombosis, and they could increase the risk of hematoma [15].

In this study, we clinically researched patients who underwent free tissue transfer surgery and analyzed the results based on the perioperative administration of low-dose heparin for 5 or 7 days, involving the period in which thrombosis typically occurred after free flap reconstruction [6]. Moreover, we evaluated whether the use of low-dose heparin decreases microvascular thrombosis.

\section{METHODS}

This retrospective study reviewed 134 cases between 2011 and 2016. During this period, two departments, Plastic and Recon-

162 Copyright $\odot 2017$ The Korean Cleft Palate-Craniofacial Association 
structive Surgery and Orthopedic Surgery, performed 134 free tissue transfers in a single medical center.

According to perioperative managements, we divided these patients into two groups: one group included 33 patients who received low-dose heparin therapy that was bolus of 2,500 injection units (IU) in the operation room and postoperative infusion at the rate of $200 \mathrm{IU} /$ hour for 7 days [10], and the other group included 101 patients who did not receive heparin therapy. Patient factors, like severity of the disease, were not considered in these two groups. And whether we apply to use low-dose heparin or not was decided by the period of the surgery. We did not use low-dose heparin before 2015 and from January 2015, we used the low-dose heparin.

Patient demographics, age, sex, and body mass index were evaluated. Risk factors, such as diabetes mellitus, hypertension, cardiovascular accident, cerebrovascular disease, and smoking, were considered. Regarding the complications, we deducted a correlation between the two groups with respect to the results of flap necrosis, hematoma formation, dehiscence, and infection. The extent of flap necrosis included all partial and total necrosis. In these two groups, patients with risk factors were further analyzed for the flap necrosis rate. Statistical analysis of the results was performed using chi-square test. A $p$-value of less than 0.05 was considered statistically significant.

\section{RESULTS}

Demographic analysis is shown in Table 1. In the no-heparin group, the mean age was 55 years old and 52 years old in the lowdose heparin therapy group. The ratio of male to female was 3.21 in the no-heparin group and 2.67 in the low-dose heparin group. In comparison to the ratio of each risk factor between two groups, there was no significant difference on the risk of vascular insufficiency in two groups.

In this study, 31 cases (23.13\%) were received on head and neck, 24 (17.91\%) were on upper extremities, 30 (22.39\%) were on lower legs, 37 (27.61\%) were on feet (Table 2). In the cases of head and neck, flap necrosis revealed 6 cases (19.4\%), and 16 cases (21.6\%) was flap necrosis in low extremity included in knee, lower legs and feet.
The overall flap necrosis rate was 6 cases $(18.18 \%)$ in the lowdose heparin group and 16 cases (15.84\%) in the no-heparin group. The flap necrosis rate showed no significant difference ( $p=0.75$; odds ratio, $1.18 ; 95 \%$ confidence interval [CI], 0.42 to 3.32) (Table 3). There was no significant difference regarding the complications of hematoma formation ( $p=0.66$; odds ratio, 0.80 ; 95\% CI, 0.29 to 2.18 ), dehiscence, and infection ( $p=0.86 ; p=0.15)$ (Table 3). There were 5 cases (15.15\%) in the low-dose heparin group and 14 cases with hematoma (13.86\%) in the no-heparin group. The number of dehiscence cases was 9 (8.91\%) and 4 (12.12\%), respectively; the number of infection cases was $9(8.91 \%)$ and $2(6.06 \%)$, respectively.

Table 1. Demographic analysis in patients with free flap

\begin{tabular}{lcc} 
Variables & Low-dose heparin & No-heparin \\
\hline Total patients & 33 & 101 \\
Age $(\mathrm{yr})$ & 52.00 & 55.09 \\
\hline Sex male/female ratio & $24: 9=2.67$ & $77: 24=3.21$ \\
\hline Body mass index & 23.778 & 23.248 \\
\hline Diabetes mellitus & $3(9.09)$ & $24(23.76)$ \\
Hypertension & $8(24.24)$ & $28(27.72)$ \\
Cardiovascular disease & 3 & 2 \\
Infarction & 1 & $45(44.55)$ \\
\hline Smoke & $21(63.64)$ & \\
\hline
\end{tabular}

Values are presented as number (\%).

Table 2. The sites of donor \& recipient

\begin{tabular}{lccc} 
Donor & Number & Recipient & Number \\
\hline Anterolateral thigh & 83 & Head \& neck & 31 \\
\hline Latissimus dorsi & 18 & Upper extremity & 24 \\
\hline Radial forearm & 18 & Breast & 5 \\
\hline Rectus abdominis & 5 & Knee & 7 \\
\hline Fibular & 4 & Lower leg & 30 \\
Gracilis & 3 & Foot & 37 \\
\hline Other & 3 & & \\
\hline
\end{tabular}

Table 3. Flap necrosis and complication rate

\begin{tabular}{lccc} 
Complications & $\begin{array}{c}\text { Low-dose heparin } \\
(n=33)\end{array}$ & $\begin{array}{c}\text { No-heparin } \\
(n=101)\end{array}$ & $p$-value \\
\hline Necrosis & $6(18.18)$ & $16(15.84)$ & 0.75 \\
Hematoma & $5(15.15)$ & $14(13.86)$ & 0.66 \\
Dehiscence & $4(12.12)$ & $9(8.91)$ & 0.86 \\
Infection & $2(6.06)$ & $9(8.91)$ & 0.15 \\
\hline
\end{tabular}

Values are presented as number (\%). 
Table 4. Risk factor of flap necrosis

\begin{tabular}{lccc} 
Risk factors & Low-dose heparin & No-heparin & $p$-value \\
\hline Diabetes mellitus & $0 / 3$ & $5 / 24(20.83)$ & 0.98 \\
Hypertension & $1 / 8(12.5)$ & $5 / 28(17.86)$ & 0.97 \\
Smoke & $3 / 21(14.29)$ & $6 / 45(13.33)$ & 0.92 \\
$\begin{array}{l}\text { Cardiovascular } \\
\text { disease }\end{array}$ & $0 / 3$ & $0 / 2$ & - \\
Infarction & $0 / 1$ & $0 / 1$ & - \\
\hline
\end{tabular}

Values are presented as number (\%).

Risk factors of flap necrosis in patients were analyzed (Table 4). There was no significant difference $(p=0.98 ; p=0.97 ; p=0.92)$ of the flap necrosis rate regarding diabetes mellitus, hypertension, smoking, cardiovascular accident, and cerebrovascular disease between the two groups. Low-dose heparin did not have a positive effect on the increase of flap survival rate in high-risk patients compared with the controls.

\section{DISCUSSION}

After suggesting that antithrombotic agents could increase the patency of vessels in the free flap [16], microsurgeons have applied these agents to improve flap necrosis. Although there have been various studies to date evaluating whether antithrombotics can prevent flap failure in microvascular surgery [17-24], little clinical evidence has been demonstrated. Nevertheless, about $96 \%$ of microsurgeons actually apply antithrombotic agents for free flaps [11].

Insufficient clinical evidence may be due to various antithrombotic agents and protocols being applied by various medical center and microsurgeons [17-24]. Among them, we emphasized what we have applied in our medical center; low-dose heparin (bolus of 2,500 IU in the operation room and postoperative infusion at the rate of $200 \mathrm{IU} /$ hour for 7 days), which was known to decrease flap necrosis rate and have low incidence of hematoma formation [10].

The main role of heparin is to encourage binding of antithrombin III to thrombin, and to inactivate other coagulation factors, such as $\mathrm{Xa}$ [25]. Due to the inactivation, fibrinogen cannot be changed to fibrin, and as a result, it leads to a decrease in the formation of blood clot or thrombus [10].
In this study, we investigated whether low-dose heparin is related to the improvement of flap necrosis. There was no significant difference in the flap necrosis rates between low-dose heparin group and no-heparin group. This suggests that heparin may not be the main responsible factor for the prevention of flap necrosis. It is because flap necrosis was not decided by only one factor such as thrombosis. There are various factors related to flap necrosis such as kinks, twists, and tension of the pedicle or flap [26].

In a comparison between the two groups, the low-dose heparin group did not show a significantly increased rate of hematoma formation. This suggests that low-dose heparin has no significant effect on the formation of hematoma. This is confirmed by the following. The hematoma rate of low-dose heparin group was the same as that of no-heparin group, and in Kroll et al.s [10] study, the hematoma rate of low-dose heparin group was significantly lower than that of high-dose heparin group.

Our study has several strengths compared with other studies. In many studies, the most common recipient site for the free flap was the head and neck $[12,13,20,22,24]$, followed by the breast or lower extremity $[18,22,24]$. We applied the free flap not only to the head and neck, but also to the lower leg, foot, and hand. Moreover, by using low-dose heparin, we found a lower rate of complications, such as hematoma formation.

However, there are some limitations to consider in this present study. First, the chart review was performed retrospectively. However, the data related to flap failure and hematoma formation in the free flap were collected prospectively; therefore, we increased the probability of data. Second, the use of low-dose heparin was dependent on the preference of each surgeon. Although there were various methods, such as intraoperative bolus only, postoperative high-dose heparin infusion etc., the most effective method with low-dose heparin was used during the perioperative period [10]. Third, prostaglandin-E1 was also used in all cases. Therefore, there was no control group in which the prostaglandin-E1 was not used. Fourth, there were a few confounding factors between the two groups. Although the difference was not statistically significant, the no-heparin group had more diabetes patients and hypertension patients than the other group.

Our study suggests that low-dose heparin may not play the 
main role in influencing the outcome of free flaps. Patients not receiving heparin showed a comparable free flap survival rate. Postoperative low-dose heparin therapy may not be a useful therapeutic option in patients undergoing microvascular reconstruction.

\section{REFERENCES}

1. Seidenberg B, Rosenak SS, Hurwitt ES, Som ML. Immediate reconstruction of the cervical esophagus by a revascularized isolated jejunal segment. Ann Surg 1959;149:162-71.

2. McLean DH, Buncke HJ Jr. Autotransplant of omentum to a large scalp defect, with microsurgical revascularization. Plast Reconstr Surg 1972;49:268-74.

3. Khouri RK, Cooley BC, Kunselman AR, Landis JR, Yeramian P, Ingram D, et al. A prospective study of microvascular free-flap surgery and outcome. Plast Reconstr Surg 1998;102:711-21.

4. Bui DT, Cordeiro PG, Hu QY, Disa JJ, Pusic A, Mehrara BJ. Free flap reexploration: indications, treatment, and outcomes in 1193 free flaps. Plast Reconstr Surg 2007;119:2092-100.

5. Yii NW, Evans GR, Miller MJ, Reece GP, Langstein H, Chang D, et al. Thrombolytic therapy: what is its role in free flap salvage? Ann Plast Surg 2001;46:601-4.

6. Kroll SS, Schusterman MA, Reece GP, Miller MJ, Evans GR, Robb GL, et al. Timing of pedicle thrombosis and flap loss after free-tissue transfer. Plast Reconstr Surg 1996;98:1230-3.

7. Brown JS, Devine JC, Magennis P, Sillifant P, Rogers SN, Vaughan ED. Factors that influence the outcome of salvage in free tissue transfer. Br J Oral Maxillofac Surg 2003;41:16-20.

8. Johnson PC, Barker JH. Thrombosis and antithrombotic therapy in microvascular surgery. Clin Plast Surg 1992;19:799-807.

9. Davies DM. A world survey of anticoagulation practice in clinical microvascular surgery. Br J Plast Surg 1982;35:96-9.

10. Kroll SS, Miller MJ, Reece GP, Baldwin BJ, Robb GL, Bengtson BP, et al. Anticoagulants and hematomas in free flap surgery. Plast Reconstr Surg 1995;96:643-7.

11. Glicksman A, Ferder M, Casale P, Posner J, Kim R, Strauch B. 1457 years of microsurgical experience. Plast Reconstr Surg 1997;100:35563.

12. Riva FM, Chen YC, Tan NC, Lin PY, Tsai YT, Chang HW, et al. The outcome of prostaglandin-E1 and dextran-40 compared to no antithrombotic therapy in head and neck free tissue transfer: analysis of 1,351 cases in a single center. Microsurgery 2012;32:339-43.

13. Lighthall JG, Cain R, Ghanem TA, Wax MK. Effect of postoperative aspirin on outcomes in microvascular free tissue transfer surgery. Otolaryngol Head Neck Surg 2013;148:40-6.

14. Xipoleas G, Levine E, Silver L, Koch RM, Taub PJ. A survey of microvascular protocols for lower-extremity free tissue transfer I: perioperative anticoagulation. Ann Plast Surg 2007;59:311-5.

15. Lee KT, Mun GH. The efficacy of postoperative antithrombotics in free flap surgery: a systematic review and meta-analysis. Plast Reconstr Surg 2015;135:1124-39.

16. Ketchum LD. Pharmacological alterations in the clotting mechanism: use in microvascular surgery. J Hand Surg Am 1978;3:407-15.

17. Ashjian P, Chen CM, Pusic A, Disa JJ, Cordeiro PG, Mehrara BJ. The effect of postoperative anticoagulation on microvascular thrombosis. Ann Plast Surg 2007;59:36-9.

18. Pugh CM, Dennis RH 2nd, Massac EA. Evaluation of intraoperative anticoagulants in microvascular free-flap surgery. J Natl Med Assoc 1996;88:655-7.

19. Disa JJ, Polvora VP, Pusic AL, Singh B, Cordeiro PG. Dextran-related complications in head and neck microsurgery: do the benefits outweigh the risks? A prospective randomized analysis. Plast Reconstr Surg 2003;112:1534-9.

20. Sun TB, Chien SH, Lee JT, Cheng LF, Hsu LP, Chen PR. Is dextran infusion as an antithrombotic agent necessary in microvascular reconstruction of the upper aerodigestive tract? J Reconstr Microsurg 2003; 19:463-6.

21. Brands MT, van den Bosch SC, Dieleman FJ, Berge SJ, Merkx MA. Prevention of thrombosis after microvascular tissue transfer in the head and neck. A review of the literature and the state of affairs in Dutch Head and Neck Cancer Centers. Int J Oral Maxillofac Surg 2010;39:101-6.

22. Lee KT, Jeon BJ, Lim SY, Pyon JK, Bang SI, Oh KS, et al. The effects of ketorolac on microvascular thrombosis in lower extremity reconstruction. Plast Reconstr Surg 2012;129:1322-7.

23. Jayaprasad K, Mathew J, Thankappan K, Sharma M, Duraisamy S, Rajan S, et al. Safety and efficacy of low molecular weight dextran (dextran 40) in head and neck free flap reconstruction. J Reconstr Microsurg 2013;29:443-8.

24. Enajat M, Aziz Mohammadi M, Debeij J, van der Hulst RR, Mureau MA. Effect of acetylsalicylic acid on microvascular thrombosis in autologous breast reconstruction. J Reconstr Microsurg 2014;30:65-70.

25. Mahadoo J, Heibert L, Jaques LB. Vascular sequestration of heparin. Thromb Res 1978;12:79-90.

26. Ozbek MR, Deune EG, Cooley BC, Khouri RK. Experimental reproduction of free flap errors: a new model of thrombosis. Ann Plast Surg 1994;32:474-7. 